\title{
A patient with reflex myoclonus and muscle rigidity: "jerking stiff-man syndrome"
}

\author{
P N LEIGH, J C ROTHWELL, M TRAUB, AND C D MARSDEN \\ From the University Department of Neurology, King's College Hospital Medical School and Institute of \\ Psychiatry, London
}

SUMMARY A patient with progressive muscular rigidity associated with reflex myoclonus is described. The muscular rigidity was predominantly axial, and the myoclonic jerks affected axial and leg muscles. Jerks occurred either spontaneously, or in response to touch to the perioral region, or to stretch of head and neck muscles. Physiological investigations suggested that the myoclonus originated in the medulla and was mediated by fast-conducting pathways upwards through the brainstem and down the spinal cord. The relationship of this condition to other types of muscular rigidity with and without myoclonus is discussed.

Myoclonus, which occurs in a wide variety of neurological disorders, describes muscle jerks occurring spontaneously or triggered by a variety of sensory stimuli. The latter, reflex myoclonus, has been divided into two main categories on physiological grounds-a "reticular" reflex type and a "cortical" reflex type. ${ }^{12}$ This paper describes a patient with an unusual form of myoclonic jerking in association with progressive muscular stiffness and evidence of a lower brainstem lesion, in whom the physiological findings were typical neither of reticular reflex nor cortical reflex myoclonus.

\section{Case history (CU, MH783595)}

A man, 38 years old at the time of investigation, following an appendicectomy at the age of 28 years, noted some stiffness and pain in his lower back, both of which gradually increased. About five years after the onset, the rigidity began to involve his legs and he became progressively more unsteady on his feet. One year before investigation the patient developed widespread intermittent, painful, stereotyped myoclonic jerks. They affected predominantly the axial musculature, particularly the paraspinal and abdominal muscles, and the legs where they involved mainly the hip abductors and triceps surae. Before the patient was treated with oral diazepam he suffered episodes of repeated myoclonic jerks about once every two to three seconds, in bouts which lasted up to five hours occurring about three

Address for reprint requests: Dr PN Leigh, Department of Neurology, Institute of Psychiatry, De Crespigny Park, Denmark Hill, London SE5 8AF.

Accepted 15 May 1980 times per day. These attacks usually occurred spontaneously (except in sleep) but sometimes they were precipitated by micturition or sudden voluntary movements. Each episode caused profound distress and sweating. They were arrested within seconds by intravenous injection of three to five $\mathrm{mg}$ of diazepam. At the time of electromyographic (EMG) studies the patient was taking oral diazepam (30 $\mathrm{mg} /$ day), which markedly reduced his spasticity and abolished his spasms.

On examination, at the time of admission, his gait was broad-based and ataxic with a marked lordosis and a spine fixed by muscle spasm. Eye movements were full, but he had a consistent downbeating jerk nystagmus on lateral and up gaze. The jaw jerk was brisk and elicited a widespread myoclonic jerk. There were no other cranial nerve abnormalities. The upper limbs were mildly spastic, with increased tendon jerks, but with no loss of power or incoordination. The abdominal and paraspinal muscles were rigid. In the legs there was pronounced increase of tone in all muscle groups, both flexors and extensors, although maximal in quadriceps and triceps surae; power in hip flexors was mildly reduced but elsewhere was normal. All tendon jerks in the lower limbs were grossly exaggerated and there was knee and ankle clonus, but no classical clasp knife response could be elicited. The plantar responses were down-going and the abdominal reflexes were present. No sensory abnormalities were detected and higher mental functions were unaffected.

A CT scan and an air encephalogram demonstrated an enlarged fourth ventricle and marked cerebellar atrophy. Other routine investigations, including the electroencephalogram (EEG), visual evoked responses, serology, plasma electrolytics and calcium studies, serum copper and routine examination of 
the cerebrospinal fluid were normal. Electromyographic (EMG) studies using concentric needle electrodes revealed normal activity in biceps and triceps brachii, pectoralis major, vastus medialis and tibialis anterior muscles. However, continuous activity of normal motor units, unaffected by attempted relaxation, was recorded from erector spinae. Motor nerve conduction velocities in median and lateral popliteal nerves were normal.

We were not able to stop the patient's intake of diazepam for more than 48 hours, so we could not investigate spontaneous myoclonic jerks. However, a tap with a tendon hammer to the jaw, face, head and back, touch to the chin and to the upper or lower lip, and electrical stimulation of the supraorbital nerves all caused myoclonic jerks, which we could study.

\section{Methods}

The EMG was recorded from various sites using silver/silver chloride surface electrodes. The EEG was recorded from unipolar electrodes 7 $\mathrm{cm}$ and $11 \mathrm{~cm}$ lateral to the vertex referred to linked ear electrodes. Signals were pre-amplified by Devices 3160 amplifiers and were fed into a PDP 12 computer, which was triggered at the same time as the stimulus that elicited myoclonic jerks. Data were collected in single trials or in averages of 128 trials.

\section{Results}

\section{EMG studies}

When the patient had been without diazepam for 48 hours, myoclonic jerks were elicited by light taps to the skin surrounding the mouth and chin. Pin pricks or other noxious stimuli produced no response from this region. Fig $1 \mathrm{~A}$ illus- trates the electromyographic form and latency of these jerks. The average latency for each muscle is shown in table 1. The EMG of jerks in orbicularis oculi, masseter and triceps surae always was a synchronous action potential, whereas other muscles showed more prolonged bursts although never longer than $50 \mathrm{~ms}$.

Myoclonic jerks with the same form and latency also could be elicited by tendon taps to the jaw, although in this instance the masseter EMG records also contained a tendon jerk response some $8 \mathrm{~ms}$ earlier than the first response to tactile stimuli (fig 1B). Tendon taps to the head and upper back evoked myoclonic jerks from a much larger input zone than for purely tactile stimuli. Fig $2 \mathrm{~A}$ shows a single jerk elicited by briskly striking the back of the head with a tendon hammer whilst the patient was seated. When the head was manually braced, therefore reducing muscle stretch, the response was markedly decreased (fig 2B).

Jerks also were produced by electrical stimulation of the supraorbital nerve at strengths sufficient to evoke both the $R 1$ and $R 2$ response in orbicularis oculi. The EMG responses coincid-

Table 1 Time of onset of muscle jerk measured from the start of muscle activity in masseter. Stimuli were light taps to the upper lip only. Mean latencies in $\mathrm{ms} \pm$ standard error

\begin{tabular}{lll}
\hline Orbicularis oculi & $-1 \pm 0 \cdot 2$ & $(\mathrm{n}=46)$ \\
Sternocleidomastoid & $-2 \cdot 9 \pm 0 \cdot 25$ & $(\mathrm{n}=39)$ \\
Erector spinae & $+4 \cdot 2 \pm 0 \cdot 8$ & $(\mathrm{n}=8)$ \\
Tensor fascia lata & $+20 \cdot 5 \pm 1 \cdot 1$ & $(\mathrm{n}=9)$ \\
Triceps surae & $+27 \pm 0 \cdot 35$ & $(\mathrm{n}=45)$
\end{tabular}

Mean latency to onset of masseter jerk, taken from stimulus was $17 \cdot 2 \pm 0 \cdot 25 \mathrm{~ms}(\mathrm{n}=54)$.
A

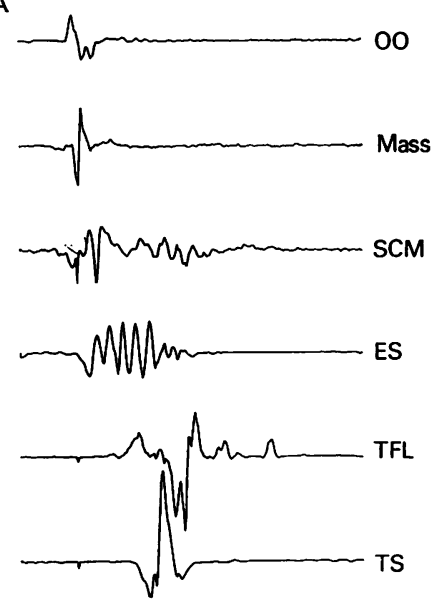

B

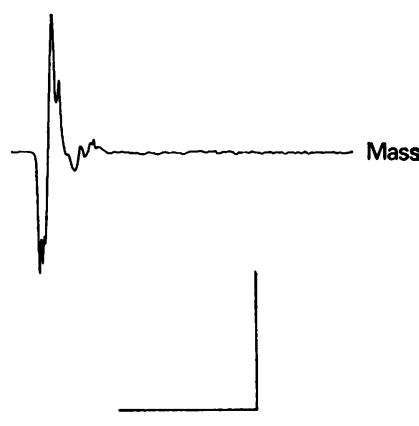

Fig 1 EMG records of $(A)$ a single myoclonic jerk in the face and axial musculature produced by a light tap on the lips with a tendon hammer and $(B)$ a single tendon jerk response in the masseter muscle after briskly striking the lower jaw. OO, orbicularis oculi; Mass, masseter; SCM, sternocleiodmastoid; $E S$, erector spinae; $T F L$, tensor fascia lata; $T S$, triceps surae, all from the left side. Sweeps triggered by the stimulus. Horizontal calibration $50 \mathrm{~ms}$; vertical calibration $2 \mathrm{mV}$ (OO and TS), $0.4 \mathrm{mV}$ (Mass, $S C M, T F L), 4 m V(E S)$ 
A

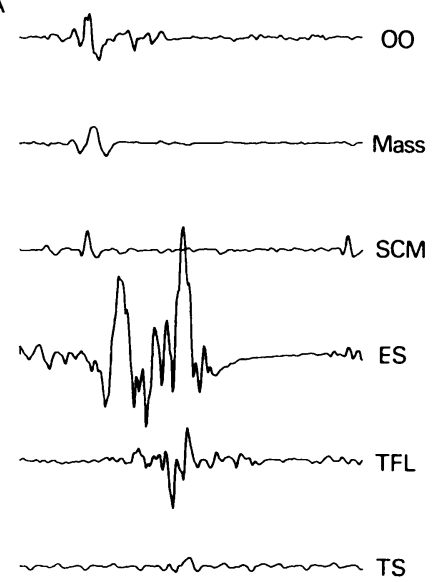

B
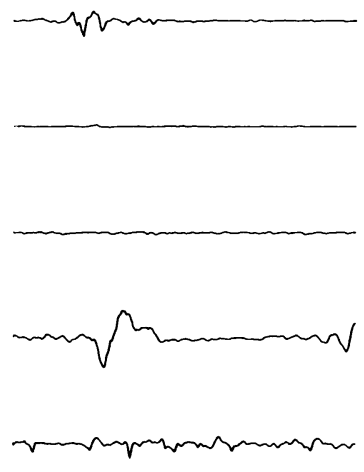

Fig 2 EMG records of a single myoclonic jerk produced by striking the back of the head with a tendon hammer. $A$, usual response; $B$, with the head braced manually to prevent muscle stretch. Sweep triggered by contact of the hammer. Horizontal calibration, $50 \mathrm{~ms}$; vertical calibration. $0.8 \mathrm{mV}$. ing with the myoclonic jerks began some $55 \mathrm{~ms}$ after the stimulus in erector spinae, abdominal muscles and triceps surae, and those in the sternocleidomastoid by over $60 \mathrm{~ms}$. No obvious

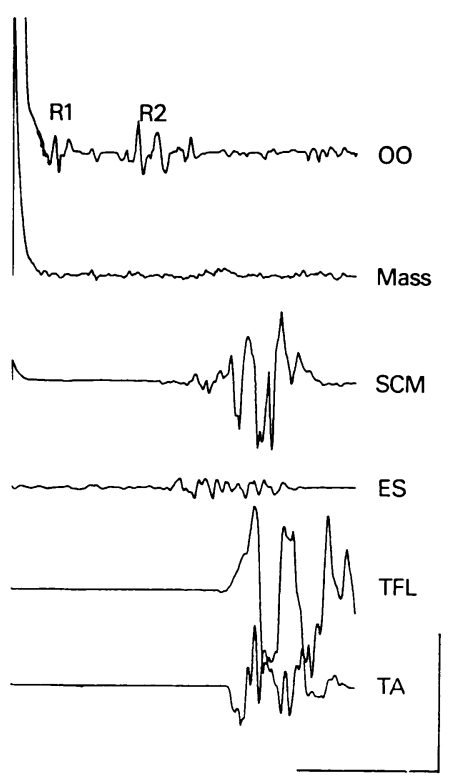

Fig 3 EMG records of the response to a single electrical shock to the supraorbital nerve, which triggered the sweep.The $R 1$ and $R 2$ responses in $O O$ are labelled. Horizontal calibration, $50 \mathrm{~ms}$; vertical calibration, $0.2 \mathrm{mV}$, except for $\mathrm{OO}$ $(0 \cdot 1 \mathrm{mV})$. response occurred in masseter using this form of stimulation (fig 3 ).

\section{EEG studies}

Light touches to the upper lip evoked widespread EEG potentials which preceded the earliest jerk response in the sternocleidomastoid (fig 4). The large first positive wave had a latency to onset of $8 \mathrm{~ms}$ but the later waves were contaminated with muscle artefact from the jerk itself. Sensory evoked potentials elicited by median nerve stimulation were normal.

\section{Discussion}

Two features dominate this patient's history, namely muscular rigidity and myoclonic jerks. Stiffness and rigidity preceded the myoclonus by nine years and had gradually progressed. The stiffness had some features of a classical "pyramidal" syndrome (spasticity in the limbs, increased tendon reflexes), but other features, such as the marked rigidity of para-spinal and abdominal muscles, preserved abdominal reflexes, and flexor plantar responses, would point to mechanisms other than "pyramidal" damage.

Muscular stiffness and rigidity similar in some respects to that seen in our patient is a feature of the stiff-man syndrome, ${ }^{34}$ the salient features of which are symmetrical rigidity of axial and proximal limb muscles, with muscular spasms. The latter may be evoked by emotional or sensory stimuli, and tend to build up and lessen over a matter of minutes. They are not usually myoclonic in the sense used in this paper, although two patients with muscular rigidity and 


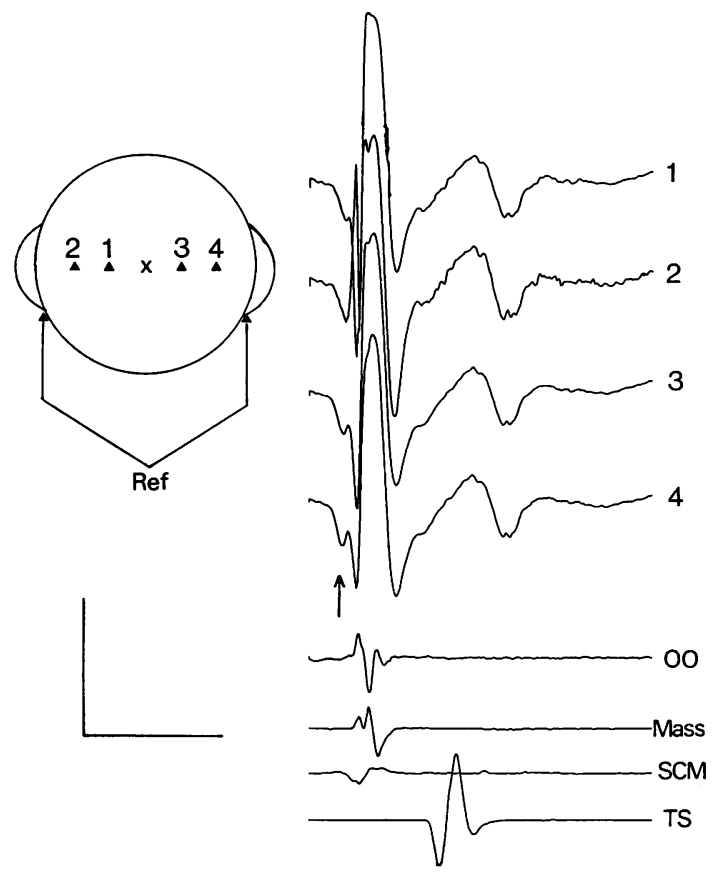

Fig 4 Average EEG (upper records) and EMG (lower records) responses to 25 light taps to the upper lip which triggered the sweep. Montage for the EEG electrodes is shown in the inset with $4 \mathrm{~cm}$ spacing between electrodes. The first positive wave, preceding the muscle jerk artefact in the EEG records, is arrowed. Horizontal calibration, $50 \mathrm{~ms}$; vertical calibration, $200 \mu \mathrm{V}$ (EEG channels), $0.4 \mathrm{mV}$ (EMG channels).

spasms in association with nocturnal myoclonus have been described. ${ }^{5}$ Neurological abnormalities generally are absent, although brisk tendon reflexes and extensor plantar responses have been described. Pathological studies have failed to reveal significant abnormality of the brain or spinal cord. ${ }^{6} 78$ On clinical grounds our patient would not be acceptable as an example of stiffman syndrome, since he has prominent brainstem signs.

Muscular rigidity and spasms also occur in the syndrome of continuous muscle fibre activity, ${ }^{9}$ thought to be due to a disorder of the motor end plate and terminal portion of the motor nerve. 910 Patients with this disorder show impaired relaxation after contraction with transient improvement after repeated contraction, cramps involving predominantly the extremities, myokymia or fasciculation, and in some cases, distal muscle wasting. Brainstem and long tract signs are not seen. Patients usually improve with phenytoin, and spontaneous gradual resolution may occur. ${ }^{1011}$ These features differentiate this condition from that of our patient.

Rhythmic myoclonus, with or without muscular rigidity, has been described with spinal trauma, ${ }^{12}$ following surgery for a spinal developmental abnormality, ${ }^{13}$ spinal tumour, ${ }^{14}$ presumed viral infection of the spinal cord, ${ }^{15} 16$ and with brainstem tumour. ${ }^{17}$ The jerking in such cases usually is localised, continues with fairly constant frequency for prolonged periods, often persisting during sleep, and is little altered by sensory or emotional stimuli. It has been termed "segmental myoclonus" by Halliday. ${ }^{13}$ In our patient, physical signs and investigations pointed clearly to an atrophic process involving lower brainstem and cerebellum, and although he had bouts of rhythmic jerking, the following features differentiated his myoclonus from segmental myoclonus: his jerks could readily be elicited by muscle stretch and by touch to the perioral region, were fairly generalised and symmetrical, and did not persist in sleep.

A disorder with close similarities to our case, with generalised rigidity and stimulus-sensitive spasms, has been described in association with progressive encephalomyelitis. ${ }^{18-21}$ The muscular rigidity in these five cases was similar to that seen in our patient, although the spasms were more prolonged than typical myoclonic jerks in four of the cases. Pathologically the lower brainstem reticular function was particularly involved, and the spinal cord was extensively but variably damaged, the only constant features being preservation of the corticospinal tracts. In the absence of pathological data we cannot be certain of the disease process in our patient, but he may have a similar slowly progressive encephalomyelitis. The length of history might argue against this, the longest interval between onset of symptoms and death in the cases mentioned above being 38 months, but there is close similarity in the muscular rigidity and evidence of brainstem damage (see table 2). Alternatively he may have a sporadic cerebellar system degeneration.

Several features of our patient's myoclonus are unusual. The myoclonus occurred (apparently) spontaneously, and continued for prolonged periods in a rhythmic stereotyped fashion. It is possible that these bouts, in fact, were triggered by sensory stimuli such as muscle stretch, and that treatment with diazepam raised the threshold so that only individual jerks could be elicited during our investigation. The myoclonic jerks which we were able to study were stimulus 
Table 2 Comparison of features of stiff-man syndrome, progressive encephalomyelitis with rigidity, and "jerking stiff-man"

\begin{tabular}{|c|c|c|}
\hline Clinical features & Stiff-man syndrome (SMS) & $\begin{array}{l}\text { Progressive encephalomyelitis with } \\
\text { rigidity }\end{array}$ \\
\hline Course & $\begin{array}{l}\text { Subacute or gradual onset leading to } \\
\text { chronic disability or death. }\end{array}$ & $\begin{array}{l}\text { Progressive-interval from onset to } \\
\text { death } 3 \text { weeks to } 38 \text { months. }\end{array}$ \\
\hline $\begin{array}{l}\text { Characteristics } \\
\text { of rigidity }\end{array}$ & $\begin{array}{l}\text { Usually symmetrical, sustained, } \\
\text { severe; spreading from axial to } \\
\text { proximal limb muscles producing } \\
\text { "board-like" muscles with rigid } \\
\text { posture and contractures. Facial and } \\
\text { bulbar involvement occurs in about } \\
25 \% \text { of cases. }\end{array}$ & $\begin{array}{l}\text { Variable pattern of marked sustained } \\
\text { rigidity involving trunk and limb } \\
\text { muscles, and in one case, facial muscle } \\
\text { and masseters. }\end{array}$ \\
\hline Spasms & $\begin{array}{l}\text { Powerful, painful spasms precipitated } \\
\text { by sensory and emotional stimuli, } \\
\text { associated with sweating and } \\
\text { tachycardia, subsiding over seconds or } \\
\text { minutes, and relieved by iv diazepam. } \\
\text { Nocturnal myoclonus described in } 2 \\
\text { patients. }\end{array}$ & $\begin{array}{l}\text { Similar to the spasms seen in patients } \\
\text { with SMS. One patient described as } \\
\text { showing "shock-like" contractions of } \\
\text { left arm and leg spreading to } \\
\text { neighbouring muscles and subsiding } \\
\text { slowly over several seconds. Partially } \\
\text { relieved by diazepam. }\end{array}$ \\
\hline Reflex myoclonus & Not described. & Not described. \\
\hline
\end{tabular}

Other neurological Usually absent; brisk reflexes and abnormalities extensor plantar responses occasionally recorded.

CSF examination Normal.

Contrast studies or computerised tomography

Electromyography motor units in agonist and antagonist muscles at rest. No evidence of denervation or myopathy.
Present; including signs of brainstem and/or spinal cord disturbances.

Normal or elevated total protein, with normal or slightly elevated white cell count.

Normal CT in one case; normal myelogram in one case.

Continuous spontaneous activity of motor units in agonists and antagonists, disappearing on relaxation, and enhanced or provoked by sensory stimuli.
"Jerking stiff man"

Slowly progressive over 9 years. Patient unable to work but otherwise independent.

Sustained, predominantly axial rigidity with board-like paraspinal and abdominal muscles. Normal tone in arms, increased tone in legs, with distribution suggestive of spasticity. No rigidity of facial or bulbar muscles.

Increased paraxial rigidity associated with episodes of brief, repetitive myoclonic jerks.

Consistently elicited, the critical stimuli being light touch to perioral region, or stretch of head and neck muscles.

Brisk jaw jerk, downbeat nystagmus, brisk lower limb reflexes with ankle clonus, but flexor plantar responses. No sensory abnormalities.

Normal.

Pneumoencephalography and CT revealed evidence of brainstem and cerebellar atrophy.

Normal activity on voluntary movement with absence of activity at rest, in arm and leg muscles, but with continuous activity of normal motor units in erector spinae, persisting during attempted relaxation. sensitive, the critical stimuli being muscle stretch and light touch; electrical stimulation of the supraorbital nerves also elicited jerks at a longer latency. That muscle stretch was an effective stimulus was indicated by the observation that the response elicited by striking the back of the head with a tendon hammer was greatly reduced when muscle stretch was limited by bracing the head manually.

Muscle stretch and touch were only effective stimuli when applied to circumscribed areas. Thus for muscle stretch the input zone included the upper four cervical segments and the entire trigeminal area, whereas for touch, the area was even more circumscribed, being limited to the perioral region only. Another very unusual feature was the stereotyped symmetrical pattern of the jerks, involving mainly axial and proximal leg muscles, with no detectable involvement of arm muscles.

The mechanisms of myoclonus in our patient must be compared to that of other forms of stimulus sensitive myoclonus. Two categories of reflex myoclonus have been proposed, "reticular reflex" and "cortical reflex" myoclonus. ${ }^{12}$ The former is characterised by a simple form of EMG burst, involving all muscles in the body, generalised spikes in the EEG associated with but not time-locked to the jerks, long afferent but short efferent cord conduction time, upward activation of cranial nerves with the earliest event localised in the medulla, muscle stretch as the critical stimulus, and a good response to drugs tending to increase cerebral 5HT levels. Hallett and co- 
workers ${ }^{1}$ suggested that this type of myoclonus originated in the lower brainstem, probably in the reticular formation. Only one other case of this type of myoclonus elicited by touch to the trigeminal area has been described. ${ }^{22}$ The second type, "cortical reflex" myoclonus, is associated with a simple EMG burst, but the jerks are limited to the area of stimulus, are associated with large sensory evoked responses (SERs) the EEG correlate of the myoclonus being a timelocked fragment of the SER, and the critical stimulus is either touch or stretch. ${ }^{2324}$ It has been suggested that cortical reflex myoclonus is due to stretch or touch stimulating an abnormally excitable cerebral cortical mechanism, perhaps the "transcortical stretch reflex" system. ${ }^{2}$

Physiological investigation of our patient revealed that the response of a particular muscle was tightly locked to the stimulus, and to the response of other muscles involved. The earliest EMG responses occurred in the sternocleidomastoids, with conduction then occurring upwards through the brainstem, and downwards through the spinal cord. Conduction up the brainstem was rapid $-1.9 \mathrm{~ms}$ from the 11 th nerve nucleus to the 7th nerve nucleus. Efferent cord conduction appeared to be fast as judged by the latency between sternocleidomastoid (the earliest response) and erector spinae, although this is only an approximate estimate. The EEG correlate of the jerks consisted of widespread bilateral large potentials, preceding and time-locked to the earliest response in sternocleidomastoid, and representing an enlarged sensory potential evoked by the stimulus.

Our patient thus shows differences from each of the two types of reflex myoclonus described earlier, and from other patients with myoclonus and muscular rigidity reported in the literature (see table 3). The features which make him unique include the role of touch and stretch as critical stimuli. the limited input zone for eliciting jerks, the symmetrical, stereotyped and yet not completely generalised distribution of the jerks, and the association with progressive muscular stiffness. However, apart from the time-locked EEG correlate, our patient resembles a case of reticular reflex myoclonus quite closely, and he has evidence of a lower brainstem lesion with downbeat nystagmus and CT evidence of brainstem and cerebellar atrophy. The nature of the lesion is obscure, but the underlying physiological disturbance probably reflects an abnormality of the pontine and medullary reticular formation. The short and relatively fixed latency of the myoclonic response with respect to the stimuli suggests mediation by oligosynaptic pathways from the reticular formation upwards through the brainstem and down through the spinal cord.

In conclusion, our patient exhibits a unique form of reflex myoclonus with associated muscular rigidity similar to that seen in the stiffman syndrome and in encephalomyelitis with rigidity. It is likely that these syndromes represent a clinical spectrum and that the mechanism of the rigidity, spasms, and in this case myoclonus,

Table 3 Comparison of physiological types of myoclonus showing brief hypersynchronous EMG bursts

\begin{tabular}{|c|c|c|c|}
\hline Feature & "Reticular" reflex myoclonus & "Cortical" reflex myoclonus & "Jerking stiff-man" \\
\hline $\begin{array}{l}\text { Form and } \\
\text { distribution of } \\
\text { of jerking }\end{array}$ & $\begin{array}{l}\text { Generalised, involving all muscles of } \\
\text { the body, including proximal muscles. }\end{array}$ & $\begin{array}{l}\text { Focal or multifocal, distal or proximal; } \\
\text { usually limited to one part of the body. }\end{array}$ & $\begin{array}{l}\text { Stereotyped, mainly axial jerks, } \\
\text { sparing arms but involving leg } \\
\text { abductors and triceps surae. }\end{array}$ \\
\hline $\begin{array}{l}\text { Characteristics of } \\
\text { spontaneous jerks }\end{array}$ & $\begin{array}{l}\text { Occurring at rest, intensified by } \\
\text { voluntary and passive movement; } \\
\text { diminished during drowsiness, } \\
\text { absent in deep sleep. }\end{array}$ & $\begin{array}{l}\text { Usually absent when patient completely } \\
\text { relaxed; precipitated by voluntary and } \\
\text { passive movement. }\end{array}$ & $\begin{array}{l}\text { Episodes occurring apparently } \\
\text { spontaneously during day or night, } \\
\text { sometimes precipitated by movement } \\
\text { or micturition. }\end{array}$ \\
\hline $\begin{array}{l}\text { Critical stimuli } \\
\text { for reflex jerks }\end{array}$ & $\begin{array}{l}\text { Muscle stretch; one patient } \\
\text { described with post anoxic reflex } \\
\text { myoclonus elicited by touch to right } \\
\text { trigeminal area. } 22\end{array}$ & $\begin{array}{l}\text { Muscle stretch or touch to part of } \\
\text { body affected by jerking. }\end{array}$ & $\begin{array}{l}\text { Muscle stretch of head and neck } \\
\text { muscles or light touch to perioral } \\
\text { region. }\end{array}$ \\
\hline $\begin{array}{l}\text { Spread of } \\
\text { myoclonus through } \\
\text { brainstem }\end{array}$ & $\begin{array}{l}\text { Relatively slow conduction from } \\
\text { medulla upwards. }\end{array}$ & Downwards. & Rapid conduction upwards. \\
\hline EE G correlate & $\begin{array}{l}\text { Generalised spikes associated with } \\
\text { but not time-locked to the jerk. }\end{array}$ & $\begin{array}{l}\text { EEG carrelate consists of a time- } \\
\text { locked fragment of the sensory } \\
\text { evoked response, preceding jerks. }\end{array}$ & $\begin{array}{l}\text { EEG evoked response precedes } \\
\text { earliest response in sternocleido- } \\
\text { mastoids, is time-locked to jerks, } \\
\text { and representing enlarged sensory } \\
\text { evoked potential. }\end{array}$ \\
\hline
\end{tabular}


lie in relatively localised areas of the brainstem.

We are grateful to Dr JC Meadows, Atkinson Morley's Hospital and Dr David Kendall, St Helier Hospital, for allowing us to study their patient. Dr JC Rothwell and Dr M Traub were supported by the Medical Research Council and Dr PN Leigh by the Wellcome Foundation.

\section{References}

1 Hallet M, Chadwick D, Adam J, Marsden CD. Reticular reflex myoclonus: a physiological type of human post-hypoxic myoclonus. J Neurol Neurosurg Psychiatry 1977; 40:253-64.

2 Hallet M, Chadwick D, Marsden CD. Cortical reflex myoclonus. Neurology (Minneap) 1979; 29:1107-25.

3 Moersch FP, Woltman HW. Progressive fluctuating muscular rigidity and spasm ("Stiff-man syndrome"); report of a case and some observations in 13 other cases. Mayo Clin Proc 1956; 31:421-7.

4 Gordon EE, Januszko DM, Kaufman L. A critical survey of stiff-man syndrome. $A m \mathrm{~J}$ Med 1967; 42:582-99.

5 Guilleminault C, Sigwald J, Castaigne P. Sleep studies and therapeutic trial with L-Dopa in a case of stiff-man syndrome. Eur Neurol 1973; 10:89-96.

6 Martinelli P, Pazzaglia P, Mantagna $\mathrm{P}$ et al. Stiff-man syndrome associated with noctural myoclonus and epilepsy. $J$ Neurol Neurosurg Psychiatry 1978; 41:458-62.

7 Asher R. A woman with stiff-man syndrome. $\mathrm{Br}$ Med J 1958; 1:265-6.

8 Trethowan WH, Allsop JL, Turner B. The stiffman syndrome. Arch Neurol 1960; 3:448-56.

9 Isaacs H. A syndrome of continuous musclefibre activity. J Neurol Neurosurg Psychiatry 1961; 24:319-25.

10 Lütschg J, Jerusalem F, Ludin HP, Vassella F. Mumenthaler M. The syndrome of "continuous muscle fibre activity". Arch Neurol 1978; 35: 198-205.
11 Isaacs $\mathrm{H}$, Heffron JJA. The syndrome of continuous muscle-fibre activity cured: further studies. J Neurol Neurosurg Psychiatry 1974; 37:1231-5.

12 Patrikios MJ. Sur un cas d'automatisme moteur particulier des membres superieurs après traumatisme de la moelle cervicale. Rev Neurol (Paris) 1938; 69:179-88.

13 Halliday AM. The neurophysiology of myoclonic jerking-a re-appraisal. In: Charlton $\mathrm{M}$, ed. Myoclonic Seizures. Amsterdam: Excerpta Medica, 1975: 1-29.

14 Garcin R, Rondot P, Guiot G. Rhythmic myoclonus of the right arm as the presenting symptom of a spinal cord glioma. Brain 1968; 91:75-84.

15 Campbell AMG, Garland H. Subacute myoclonic spinal neuronitis. J Neurol Neurosurg Psychiatry 1956; 19:268-74.

16 Hopkins AP, Michael WF. Spinal myoclonus. J Neurol Neurosurg Psychiatry 1974; 37:112-5.

17 Avanzini G, Beluffi M, Caraceni T, Leane B. Mioclonie ritmiche scheletriche in corso $\mathrm{di}$ neurinoma dell'acustico. Riv Neurobiol 1958; 14:644-56.

18 Kasperek S, Zebrowski S. Stiff-man syndrome and encephalomyelitis. Arch Neurol 1971; 24:22-30.

19 Lhermitte F, Chain F, Escourolle R, Chedru F, Guilleminault $C$, Francoual $M$. Un nouveau cas de contracture tetaniforme distinct "du stiff-man syndrome". Rev Neurol (Paris) 1973; 128:3-21.

20 Whiteley AM, Swash M, Urich H. Progressive encephalomyelitis with rigidity. Brain 1976; 99: $27-42$.

2.1 Howell DA, Lees AJ, Toghill PJ. Spinal internuncial neurones in progressive encephalomyelitis with rigidity. $J$ Neurol Neurosurg Psychiatry 1979; 42:773-85.

22 Niedermeyer E, Bauer G, Burnite R, Reichenbach $D$. Selective stimulus sensitive myoclonus in acute cerebral anoxia. Arch Neurol 1977; 34: 365-8.

?3 Sutton CG, Mayer FR. Focal reflex myoclonus. J Neurol Neurosurg Psychiatry 1974; 37:207-17.

24 Dawson GD. Investigations on a patient subiect to myoclonic seizures after sensory stimulation. J Neurol Neurosurg Psychiatry 1947; 10:141-62. 